\title{
Discontinuous precipitation in copper base alloys
}

\author{
K T KASHYAP \\ Department of Mechanical Engineering, PES Institute of Technology, Bangalore 560 085, India
}

MS received 12 June 2008; revised 4 August 2009

\begin{abstract}
Discontinuous precipitation (DP) is associated with grain boundary migration in the wake of which alternate plates of the precipitate and the depleted matrix form. Some copper base alloys show DP while others do not. In this paper the misfit strain parameter, $\eta$, has been calculated and predicted that if $100 \eta> \pm 0 \cdot 1$, DP is observed. This criterion points to diffusional coherency strain theory to be the operative mechanism for DP.
\end{abstract}

Keywords. Precipitation; Vegard's law; copper alloys; grain boundary migration.

\section{Introduction}

Discontinuous precipitation (DP) occurs in many alloy systems under certain conditions. DP is characterized by the motion of the grain boundary in the wake of which alternate lamellae of the precipitate and the depleted matrix is obtained. DP is often associated with a drop in hardness and yield strength since it grows at the expense of continuous precipitates. Although the driving force for DP is solid supersaturation, i.e. the chemical driving force, the fundamental problem for the driving force for grain boundary (GB) migration, exists.

Therefore, Yoon and Hupman (1981) proposed the diffusional coherency strain theory for motion of GBs during DP. The theory supposes a thin diffusion layer ahead of the grain boundary which is coherent with the matrix. The coherency strain energy raises the chemical potential of the atoms in the neighbouring grain due to which atoms jump across the GB thus affecting GB migration. Chung et al (1992) verified diffusional coherency strain theory in DP in $\mathrm{Al}-\mathrm{Zn}$ system. Later on, Kashyap et al (2000a) verified diffusional coherency strain theory in $\mathrm{Mg}-\mathrm{Al}$ system one by adding $1 \mathrm{wt} \% \mathrm{~Pb}$ to the alloy which retarded DP and the other by applying applied stresses during DP.

In this paper, calculations are performed by using misfit parameter in systems of copper based alloys, some of which undergo DP and some do not show DP. A scientific rationale is worked out for the prediction of DP in copper base alloys.

\footnotetext{
*Author for correspondence (ktkashyap@yahoo.com)
}

\section{Results, discussion and calculations}

The main scientific problem in discontinuous precipitation is the nature of the driving force for GB migration although solute supersaturation is the chemical driving force for precipitation. The coupling driving has been tested by Chung et al (1992) and Kashyap et al (2000b) to be diffusional coherency strain theory.

The diffusional coherency strain theory assumes a thin diffusion layer ahead of the grain boundary of thickness, $D / V$, where $D$ is the diffusion coefficient of solute in the matrix $\left(\mathrm{m}^{2} / \mathrm{s}\right)$ and $V$ the velocity of grain boundary $(\mathrm{m} / \mathrm{s})$.

The elastic strain energy is $E_{\text {elastic }}=E \delta^{2}$, where $E$ is the Young's modulus of the matrix and $\delta$ the misfit strain.

The misfit strain is given by

$$
\delta=\eta(C s-C o),
$$

where $\eta$ is the misfit strain parameter

$$
\eta=\frac{1}{a} \frac{\mathrm{d} a}{\mathrm{~d} c}
$$

$a$ is the lattice parameter of the solvent, $\mathrm{d} a / \mathrm{d} c$ the slope of lattice parameter vs concentration curves (Vegard's law), $C s$ the concentration of solute in the diffusion layer which can be approximated as the concentration in the depleted matrix of DP and Co the concentration of solute in the matrix.

It is because of the strain energy, $E_{\mathrm{s}}$, that the chemical potential of atoms increases which makes them jump across the grain boundary thus effecting grain boundary migration during DP.

Binary copper base alloys were selected for study because data was available as to which systems undergo DP and which systems do not show DP (Gust 1970).

Table 1 lists the binary copper base alloys which show DP and which systems do not show DP. 
Table 1. Discontinuous precipitation of copper base alloys (Gust 1970).

\begin{tabular}{lc}
\hline Binary system & Discontinuous precipitation \\
\hline $\mathrm{Cu}-\mathrm{Si}$ & No \\
$\mathrm{Cu}-\mathrm{P}$ & No \\
$\mathrm{Cu}-\mathrm{Mn}$ & No \\
$\mathrm{Cu}-\mathrm{Cr}$ & No \\
$\mathrm{Cu}-\mathrm{Fe}$ & No \\
$\mathrm{Cu}-\mathrm{Co}$ & No \\
$\mathrm{Cu}-\mathrm{Ni}$ & No \\
$\mathrm{Cu}-\mathrm{Ag}$ & Yes \\
$\mathrm{Cu}-\mathrm{Cd}$ & Yes \\
$\mathrm{Cu}-\mathrm{In}$ & Yes \\
$\mathrm{Cu}-\mathrm{Sn}$ & Yes \\
$\mathrm{Cu}-\mathrm{Sb}$ & Yes \\
$\mathrm{Cu}-\mathrm{Ti}$ & Yes \\
$\mathrm{Cu}-\mathrm{Mg}$ & Yes \\
$\mathrm{Cu}-\mathrm{Be}$ & Yes \\
\hline
\end{tabular}

Table 2. Values of misfit strain parameter $\eta$ for copper base alloys.

\begin{tabular}{lll}
\hline Binary systems & DP & \multicolumn{1}{c}{$\eta(1 /$ atom\%) } \\
\hline $\mathrm{Cu}-\mathrm{Si}$ & No & Not available \\
$\mathrm{Cu}-\mathrm{P}$ & No & Not available \\
$\mathrm{Cu}-\mathrm{Mn}$ & No & +0.00105 \\
$\mathrm{Cu}-\mathrm{Cr}$ & No & +0.000866 \\
$\mathrm{Cu}-\mathrm{Fe}$ & No & +0.0006944 \\
$\mathrm{Cu}-\mathrm{Co}$ & No & $-0 \cdot 000462$ \\
$\mathrm{Cu}-\mathrm{Ni}$ & No & -0.000369 \\
$\mathrm{Cu}-\mathrm{Ag}$ & Yes & +0.001336 \\
$\mathrm{Cu}-\mathrm{Cd}$ & Yes & +0.002330 \\
$\mathrm{Cu}-\mathrm{In}$ & Yes & +0.002566 \\
$\mathrm{Cu}-\mathrm{Sn}$ & Yes & +0.00194 \\
$\mathrm{Cu}-\mathrm{Sb}$ & Yes & +0.00175 \\
$\mathrm{Cu}-\mathrm{Ti}$ & Yes & $+0 \cdot 001255$ \\
$\mathrm{Cu}-\mathrm{Mg}$ & Yes & +0.001637 \\
$\mathrm{Cu}-\mathrm{Be}$ & Yes & -0.0009 \\
\hline
\end{tabular}

The value of $\eta$ misfit strain parameter is calculated as

$$
\eta=\frac{1}{a} \frac{\mathrm{d} a}{\mathrm{~d} c}
$$

$\mathrm{d} a / \mathrm{d} c$ is calculated from the slope of ' $a$ ' vs ' $c$ ' curves which are normally straight lines (Vegard's law) i.e. $a$ is the lattice parameter $(\AA), c$ the concentration of solute in atom $\%$.

The data were taken from Pearson's Handbook (1958) and $\eta$ was calculated. The units of $\eta$ are $1 /$ atom $\%$.

This calculation of $\eta$ can be used to predict DP in copper base alloys i.e. binary $\mathrm{Cu}$ alloys. It can be observed from table 2 that the critical value of $\eta$ is 0.001 and $\eta$ is greater than \pm 0.001 and DP occurs in the binary copper base alloys. If $\eta$ is less than \pm 0.001 , DP will not occur in the copper base alloy. This crucial result can be used as indirect evidence for diffusional coherancy strain theory as, if $\eta$ is $> \pm 0.001$, misfit strain parameter $\delta$ will be large and elastic strain energy $\left(E \delta^{2}\right)$ will also be large and diffusional coherancy strain theory for DP will be validated.

\section{Conclusions}

It is found that when misfit strain parameter $\eta$ or $100 \eta$ is greater than \pm 0.001 and $\pm 0 \cdot 1$, DP occurs in copper base systems. This result is indirect evidence for diffusional coherancy strain hypothesis.

\section{Acknowledgements}

The author wishes to thank HOD, Mechanical Department, Principal and Management of PESIT, Bangalore, India, for support.

\section{References}

Chung V H, Shin M C and Yoon D N 1992 Acta Metall. 40 2177

Gust W 1970 Discontinuous precipitation in binary metallic systems (Germany: Springer Verlag)

Kashyap K T, Ramachandra C, Sujatha M and Chatterji B 2000a Bull. Mater. Sci. 2339

Kashyap K T, Ramachandra C, Bhat V and Chatterji B 2000b Bull. Mater. Sci. 23295

Pearson's Handbook 1958 Handbook of lattice spacings and structures of metals and alloys 2

Yoon D N and Hupman W J 1981 Acta Metall. 27973 